\title{
Design and Analysis of A Vortex Induced Vibration Based Oscillating Free Stream Energy Converter
}

\author{
Ratan Kumar Das ${ }^{1 *}$, Muhammad Taharat Galib ${ }^{2}$ \\ ${ }^{1}$ Department of Mechanical Engineering, Chittagong University of Engineering and Technology, Chittagong-4349, Bangladesh \\ ${ }^{2}$ Department of Mechanical Engineering, City University, Dhaka-1215, Bangladesh
}

Received: April 14, 2021, Revised: June 25, 2021, Accepted: June 27, 2021, Available Online: June 29, 2021

\begin{abstract}
The KármánVortex Shedding is one of the special types of vortex that is generated from asymmetric flow separation. For many years engineers tried to suppress the vortex shedding as it brings unnecessary motion to the static members inside the flow field. A converter model is designed and studied to harness the energy associated with this vortex shedding and convert it into usable form rather than suppressing it. It is a bluff body placed on the free stream incurring vortex-induced vibration and giving out a swinging pendulum motion. This motion is utilized to produce electricity. The model is analyzed on the free stream of water and conversion efficiency of $8.9 \%$ is achieved. A theoretical formula is derived regarding the force acting on the bluff body during the motion. Various parameters such as aspect ratio, flow velocity, lock-in delay, frequency of oscillation, etc. as well as their relations are studied by simulating the model in ANSYS FLUENT 18.1 for different configurations. From the simulated results it is obvious that as the lift force on the bluff body increases, more power generation is possible. Also, the experimental results paved the way for further study for practical large-scale implementation of the converter.
\end{abstract}

Keywords: Vortex-Induced Vibration, Oscillating Energy Converter, Free Stream Energy

This work is licensed under a Creative Commons Attribution-Non Commercial 4.0 International License.

\section{Introduction}

Renewable energy is the most developing field in modern engineering. As the limited natural resources are being perished, the world is targeting energy transformations especially renewable energy. The concept of vortex in the field of renewable energy is pretty old. But no reliable base has been structured for continuous and large-scale power generation. Vortex is a regular phenomenon in various flow fields. KármánVortex Shedding is one of the special types that is generated from asymmetric flow separation. For many years, engineers tried to suppress the vortex shedding as it brings unnecessary motions to the static members inside the flow field. In fluid dynamics, a Kármán vortex street (or a von Kármán vortex street) is a repeating pattern of swirling vortices, caused by a process known as vortex shedding, which is responsible for the unsteady separation of flow of a fluid around bluff bodies [1]. In practice, this phenomenon appears after the destabilization of the flow due mainly to the surface roughness of a bluff body. As roughness is one of the inherited properties of a body, it can surely be used for reasonable purposes. Vortex can induce vibration in a body. To extract power from the vortex, this vibration has to be augmented by proper mechanism and transformed into suitable power generating motion. Again, many of the natural sources of water are the open channel. There is a vast free stream of water available from those. A huge amount of free energy can be harvested from these flows to cope with the upcoming demand for energy. Artificial vortex can be created on these open flow channels and the desired motion can be gained.

As mentioned by Von Karman [2], Ever since Leonardo da Vinci first observed Vortex-Induced Vibration (VIV) circa $1500 \mathrm{AD}$, in the form of "Aeolian Tones," engineers have been trying to spoil vortex shedding and suppress VIV to prevent damage to equipment and structures. Further, Von Karman himself at Cal Tech proved that the Tacoma Narrows bridge collapse in 1940 was due to VIV.

Strouhal [3] first noticed and experimented on the vortex shedding in wires in 1878. He established a dimensionless number 'Strouhal Number' characterizing the oscillating flow mechanism. Dorman, et al. [4] invented a technique to improve turbine aerodynamic performances in 1968. Edwards [5] patented a wind energy converter utilizing vortex augmentation. He converted the linear momentum of wind energy into a pair of concentrated, counter-rotating, and side-by-side regions of high angular momentum to extract energy from the established regions for driving electric generators or generators therefrom. Patterson and Flechner [6] investigated an exploratory wind tunnel of a wingtip-mounted vortex turbine for vortex energy recovery in 1985. In 1990, Patterson [7] patented his experiment of extracting rotational energy from the vortex created at the aircraft wingtips which consists of a turbine with blades located in the crossflow of the vortex and attached downstream of the wingtip. From then on, operating the turbine at the vortex zone for increased efficiency was regularly researched. Jensen [8] made a concept on energy converter using imploding plasma vortex heating in late 1994. In 2008 Carney [9] patented his invention which includes a bluff body coupled to a gyroscopic electrical generator. In recent years from 2016 various projects named Vortex Bladeless by Cajas, et al. [10] are commercially started implementing large elastic columns or conical-shaped bladeless bars which vibrate due to vortex shedding that is generated by wind-column interaction. In 2008, Bernitsas, et al. [11] invented a new concept named VIVACE technology. This Vortex-Induced Vibration Aquatic Clean Energy refers to cylindrical-shaped horizontal bars that are submerged underwater undergo VIV and vibrates perpendicular to the 
direction of flow producing electricity. According to him, from wind energy, power extraction using vortex has begun long ago. Various devices were designed to extract vortex power from the flow of liquid or water in 1957, 1994, and 2006. But none of them were able to go for large-scale implementation. Vortex generation from ocean energy emerged truly from 2007.

Throughout these studies, it is seen that no attempt is taken for harnessing energy from the free stream surface of open channel flow based on VIV. Thus, in this study, a swinging vortex energy converter is designed and implemented to convert the free stream flow energy of water into electrical energy. A bluff body (cylinder) is placed on the free stream of a flow. Karman Vortex Street will be formed and a transverse vibration will occur. Electricity generation is proportional to the frequency of the vibration. From the experiment, for maximum frequency, a suitable depth to diameter ratio, correlation length, the power output of the bluff body is obtained for different flow velocities. The model is simulated using ANSYS software to get relations among various parameters in different conditions.

The reason behind the selection of open flow channels of water is to minimize the effect on the environment as well as gaining maximum efficiency in energy conversion. Also, the aquatic life has a close similarity with vorticity and their movements which ensures an undisturbed environment. As there is almost no harm in vortex power generation from the free stream and with less continuous effort, this study deserves a go for the possibility of getting sustainable renewable energy.

\section{Methodology}

The study is carried out in three steps. A converter model is designed and fabricated, the experimental setup is run to check the feasibility along with data collection and 25 individual numerical simulations have been done to analyze the performance of the model. The experimental model has a fixed geometry and it is implemented on an open channel flow where the velocity is fixed. Hence, the setup yielded some results which are used to calculate power output and efficiency. This has proved the feasibility of the proposed model. A numerical model is also designed. First, it is simulated with the same configuration as the physical one. Then the numerical model is designed using five different aspect ratios (height to diameter ratio) and for each aspect ratio, the model is simulated for five different velocities. Hence, a total of 25 individual numerical simulations is carried out. From these simulations, the relationships amongst coefficient of lift (lift force generated on the cylinder surface to the dynamic force applied on the projected area of the body by the free stream), vibration frequency, delay time, velocity, and aspect ratios are analyzed.

\subsection{Physical Model}

The design and actual fabricated model is shown in Fig. 1. The model consists of a solid cylinder that is welded at the bottom of a steel bar. A metal sheet is attached at the lower midportion of the bar. At the top of the bar, a rectangular bar magnet is attached. The cylinder has a height of $5 \mathrm{~cm}$ and a diameter of $4.5 \mathrm{~cm}$. The bar magnet has a magnetic flux density of 0.1 Tesla. The coil has 100 turns of copper wire with nickel insulation. Through the gap of the coil, the bar magnet attached with the upper portion of the converter can oscillate almost linearly. During operation, the cylindrical portion is submerged under the open channel flow up to its upper surface.

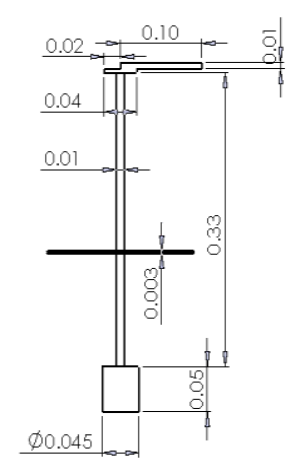

(a)

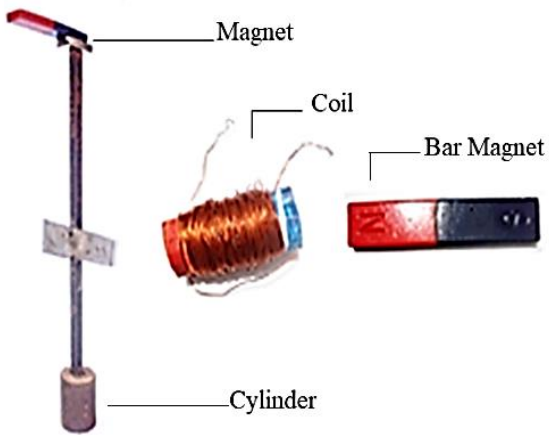

(b)
Fig. 1 (a) Design of the model and (b) Actual fabricated model with coil and magnet

Initially, the model rests on its metal sheet which hangs on two other external support rods. Due to continuous laminar flow, flow separation takes place around the cylindrical surface, and the vortex is formed accordingly. This vortex induces vibration to the cylinder, hence on the magnet. As a result, the cylinder undergoes pendulum swing being supported on the metal sheet. The magnet swings nearly with linear motion through the midspace of the coil generating electricity according to the law of Electromagnetic Induction. This is depicted in Fig. 2. The velocity of the experimental flow channel was $0.3 \mathrm{~m} / \mathrm{s}$. A multimeter is used to estimate the power generation.

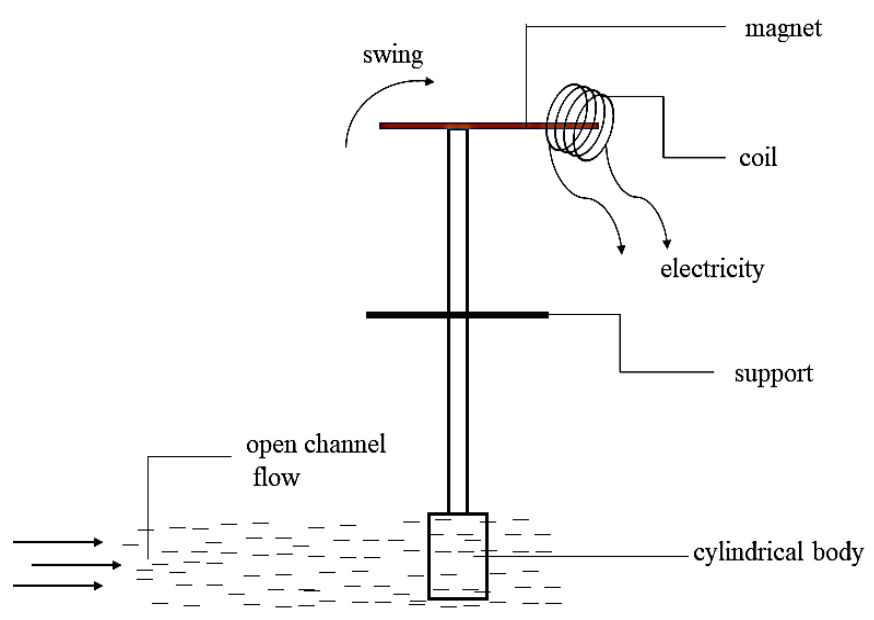

Fig. 2 Schematic diagram of the experiment

For a cylindrical body, the primary response mode is transverse to the flow. In-line oscillations of smaller magnitude are also observed in VIV and strengthen transverse oscillations [12]. As the flow velocity $V_{\infty}$ increases, lock-in for a high mass ratio system is reached when the vortex formation frequency $f_{v \text {, form }}$ is close enough to the body's natural frequency $f_{n}$, water as seen, Lock-in or vortex synchronization occurs over a broad range. The data collected from the experiment is processed using the following equations:

The frequency of the body, in general, is given by [3]

$f=0.198 \frac{V_{\infty}}{D}\left(1-\frac{19.7}{R_{e}}\right)$ 
The power of the free stream can be calculated with [11],

$P_{\infty}=\frac{1}{2} \rho V_{\infty}^{3} D L$

Power gained at output (electric power) is given by

$P_{e l c}=V I$

Efficiency can be calculated by

$\eta=\frac{P_{e l c}}{P_{\infty}} \times 100 \%$

\subsection{Numerical Model}

To study different parameters of the converter and flow region, a numerical model is developed. The model which has the same configuration and input parameters as the experimental one is shown in Fig. 3. The model is also modified for aspect ratios of $0.6,0.8,1.11,1.2$, and 1.5. For each of these aspect ratios, five different velocities are selected and simulated. The velocities are $0.3 \mathrm{~m} / \mathrm{s}, 1 \mathrm{~m} / \mathrm{s}, 2 \mathrm{~m} / \mathrm{s}, 3 \mathrm{~m} / \mathrm{s}$ and $4 \mathrm{~m} / \mathrm{s}$. The different aspect ratios are achieved by fixing the cylinder length at $0.05 \mathrm{~m}$ and changing the diameter accordingly to get the aforesaid aspect ratios. For these 5 different diameters of the cylinder, 5 different meshings are done keeping the meshing method, edge sizing, and inflation parameters the same.

The actual design is imported to ANSYS Design Modeler and various dimensional parameters are set. The rectangular portion is set as the fluid domain. The cut-out circular portion represents the outer surface of the cylinder. The cylinder is set to solid iron. The channel length is set to $0.6096 \mathrm{~m}$ and width is set to $0.3048 \mathrm{~m}$ maintaining similarity with the experimental setup. The diameter of the circle is changed as per the required aspect ratio. Meshing is carried out with ANSYS Meshing as depicted in Fig. 3. The meshing method is selected as all triangular method. Edge sizing is performed with uniform Size Function, Element Size of $0.001 \mathrm{~m}$ and Growth Rate of 1.20 . The boundary of the cylinder is inflated for increased accuracy. The inflation option is set to First Layer Thickness, First Layer Height of 0.60.0005 $\mathrm{m}$, and Maximum Layers of 30 and a Growth Rate of 1.10. The flow is set towards positive X-axis. Meshed model is opened in the FLUENT solver and various parameter is set. As for the solver type, a pressure-based solver is selected. Model is set to viscous-laminar. The boundary conditions are given as follows- inlet velocity is set as per the experiment, the two sides of the flow domain are set to the wall (applies no-slip condition), the cylinder is also set to a wall, the outlet is configured as pressure output.For the calculation of lift coefficients, corresponding reference values (area, density, and viscosity) are set according to proper aspect ratios and inlet conditions. Each calculation is allowed to run for sufficient time depending upon the lock-in time. Time step size is set to 0.01 . For convergence with sufficient accuracy, a maximum of 200 iterations per time step is set.

The plot of the lift coefficients generated for each simulation is the key to understand the force acting on the cylinder for the given conditions and parameters. As the lock-in phase is achieved, a continuous similar vibration curve of maximum amplitude is found. The peak values of those sinusoidal curves are collected which corresponds to the coefficient of lift at maximum amplitude. Also, the frequency of vibration after the lock-in is counted. The lock-in delay (time) for each velocity and aspect ratios of the model are noted too.

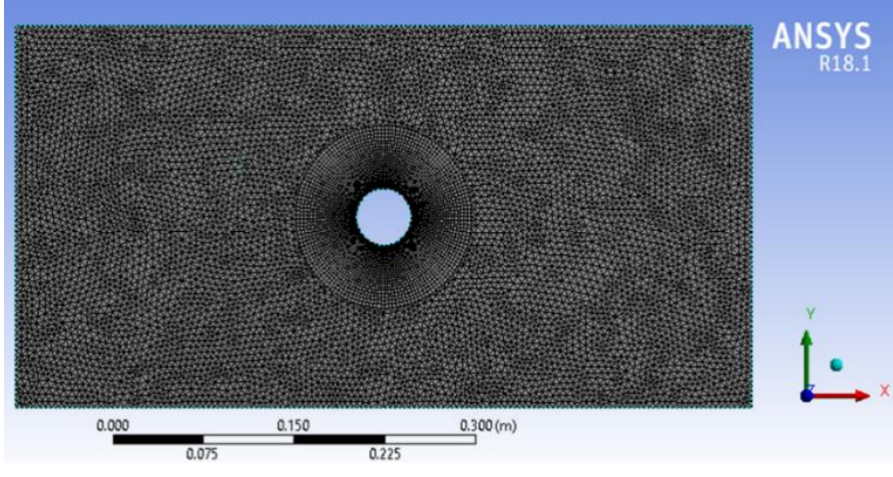

Fig. 3 Meshing of the model

\section{Results and Discussion}

\subsection{Experimental Results}

From the experimental setup, the free stream velocity of the channel is $V_{\infty}=0.3 \mathrm{~m} / \mathrm{s}$, where the Cylinder Height, $L=$ $0.05 \mathrm{~m}$; Diameter, $D=0.045 \mathrm{mand}$ the Density of water is $100 \mathrm{~kg} / \mathrm{m}^{3}$. From the multimeter, the voltage reading is $V_{r m s}=$ $3.54 \mathrm{mV}$ and the Current, $I=0.768 \mathrm{~A}$. The number of full oscillations is 10 and it took a time of $t=8.33 \mathrm{~s}$. The Lock-in Delay is $7 \mathrm{~s}$. The frequency of the converter is found to be $1.2 \mathrm{~Hz}$. Power generated by the converter is calculated to be2.715 $\mathrm{mW}$ whereas the power available from the source is calculated to be $30.375 \mathrm{~mW}$. Hence, the conversion efficiency of the designed model is $8.9 \%$. The conversion efficiency achieved by this model is satisfactory at this primary stage of development and very much affordable compared to the solar converter. This proves that the concept of harnessing free stream energy with a swinging VIV converter is feasible.

\subsection{Numerical Results}

From the numerical study, a total of 25 sets of Lift coefficient vs time charts, Streamline graphs, and pressure contours are found. Only the graphs of the numerical model which has a similar configuration with the experimental one are shown in Fig. 4. All other individual simulations for five different aspect ratios for lift coefficient, lock-in delay, and velocities yield similar sets of graphs. Values from those graphs are extracted and presented in Table 1.

The pressure contour in Fig. 4 (a) depicts that pressure is much higher at the inlet section of the cylinder surface due to stagnation. The immediate lowest pressure regions in circular forms just after the downstream portion of the cylinder represent vortex formation repetitively. The velocity streamlines in Fig. 4 (b) clearly show that the cylinder is experiencing lift force on one side and after a small time step it experiences lift force on the other side. This proves the vibration induced by the vortex. This repetitive change of direction of lift force causes the cylinder to swing along Y-axis. The value of the coefficient of lift with respect to flow time can be obtained from Fig. 4 (c). Here it is seen that the lift coefficient is inconsistent at first and it takes some time to become consistent and changes in a sinusoidal form. The time it takes to become stable is referred to as lock-in delay. Stable power conversion can be only obtained from the vibration after the lock-in. This graph also provides the number of vibrations against the time i.e. the frequency. 


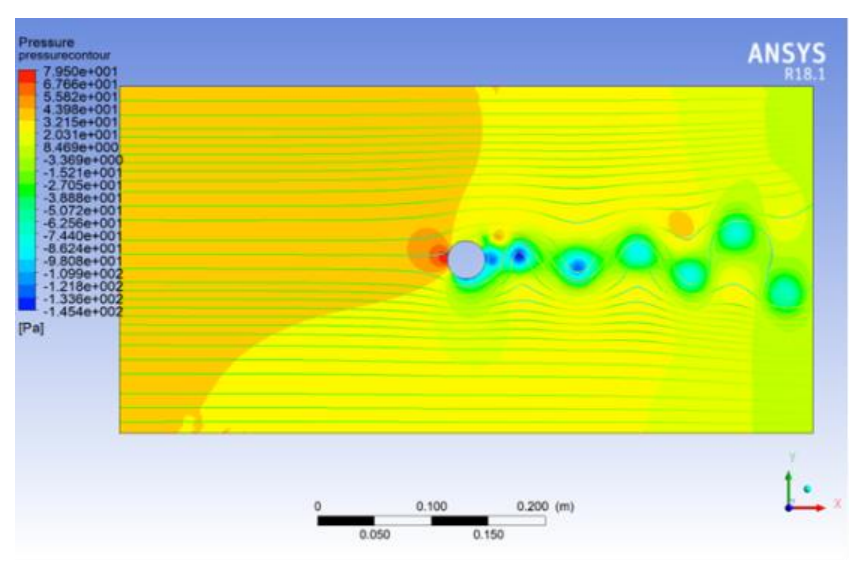

(a)

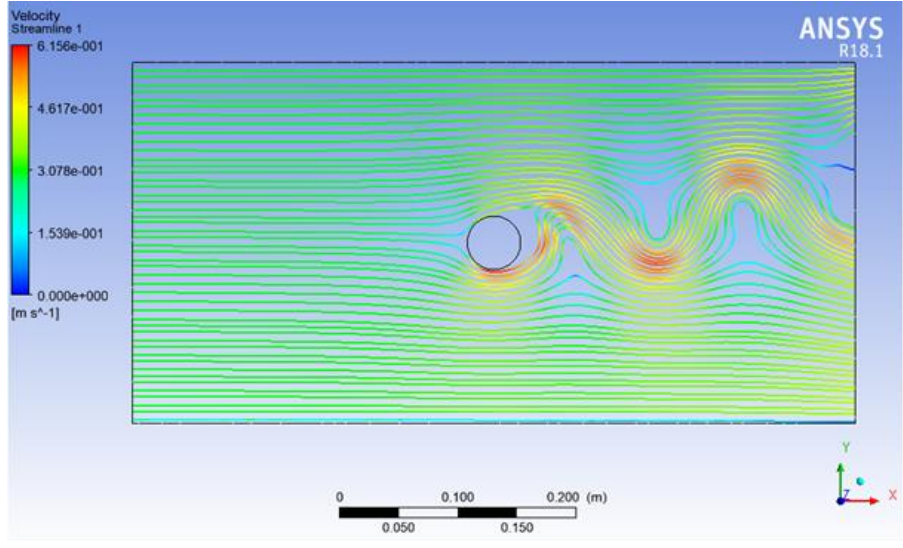

(b)

Elift_coefficien

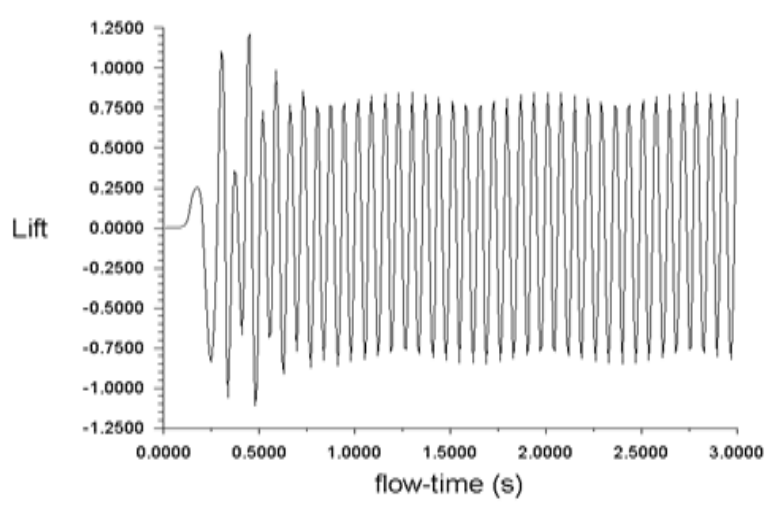

(c)

Fig. 4 Plots of (a) Pressure Distribution, (b) Velocity Streamlines, and (c) Coefficient of Lift

Table 1 Simulation results of Lock-in Delay, CL, and Frequency at different velocities

\begin{tabular}{|c|c|c|c|c|c|c|}
\hline \multirow{2}{*}{ Diameter (m) } & \multirow{2}{*}{ AR } & \multicolumn{5}{|c|}{ Lock-in Delay (s) at different Velocities } \\
\hline & & $0.3 \mathrm{~m} / \mathrm{s}$ & $1 \mathrm{~m} / \mathrm{s}$ & $2 \mathrm{~m} / \mathrm{s}$ & $3 \mathrm{~m} / \mathrm{s}$ & $4 \mathrm{~m} / \mathrm{s}$ \\
\hline 0.083 & 0.6 & 7.2 & 1.9 & 1.13 & 0.75 & 0.6 \\
\hline 0.0625 & 0.8 & 6 & 1.63 & 1.02 & 0.9 & 0.8 \\
\hline 0.045 & 1.11 & 5 & 1.6 & 0.8 & 0.65 & 0.4 \\
\hline 0.0334 & 1.5 & 4.1 & 1.5 & 1 & 0.7 & 0.6 \\
\hline 0.025 & 2 & 3.9 & 1.25 & 0.7 & 0.6 & 0.59 \\
\hline \multirow{2}{*}{ Diameter (m) } & \multirow{2}{*}{$\mathrm{AR}$} & \multicolumn{5}{|c|}{ CL at different Velocities } \\
\hline & & $0.3 \mathrm{~m} / \mathrm{s}$ & $1 \mathrm{~m} / \mathrm{s}$ & $2 \mathrm{~m} / \mathrm{s}$ & $3 \mathrm{~m} / \mathrm{s}$ & $4 \mathrm{~m} / \mathrm{s}$ \\
\hline 0.083 & 0.6 & 3.5 & 2.9 & 2.7 & 1.7 & 1.15 \\
\hline 0.0625 & 0.8 & 3.1 & 2.9 & 2 & 1.2 & 0.85 \\
\hline 0.045 & 1.11 & 3 & 2.25 & 1.25 & 0.8 & 0.5 \\
\hline 0.0334 & 1.5 & 2.5 & 1.79 & 1 & 0.6 & 0.3 \\
\hline 0.025 & 2 & 2.17 & 1.48 & 0.81 & 0.4 & 0.13 \\
\hline \multirow{2}{*}{ Diameter (m) } & \multirow{2}{*}{$\mathrm{AR}$} & \multicolumn{5}{|c|}{ Frequency $(\mathrm{Hz})$ at Different Velocities } \\
\hline & & $0.3 \mathrm{~m} / \mathrm{s}$ & $1 \mathrm{~m} / \mathrm{s}$ & $2 \mathrm{~m} / \mathrm{s}$ & $3 \mathrm{~m} / \mathrm{s}$ & $4 \mathrm{~m} / \mathrm{s}$ \\
\hline 0.083 & 0.6 & 1 & 4 & 6 & 9 & 12 \\
\hline 0.0625 & 0.8 & 1 & 4 & 8 & 11 & 14 \\
\hline 0.045 & 1.11 & 2 & 5 & 10 & 14 & 17 \\
\hline 0.0334 & 1.5 & 2.5 & 7.5 & 12 & 16 & 19 \\
\hline 0.025 & 2 & 3 & 9 & 15 & 18 & 21 \\
\hline
\end{tabular}




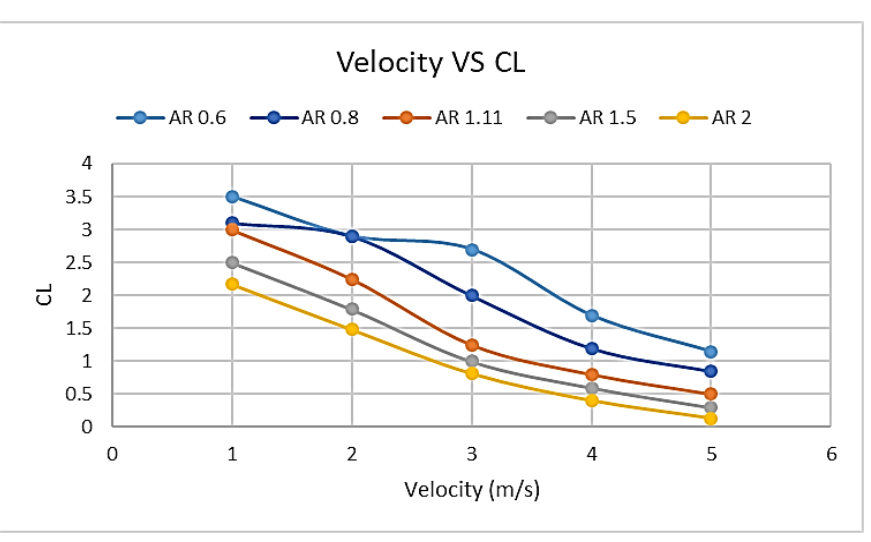

(a)

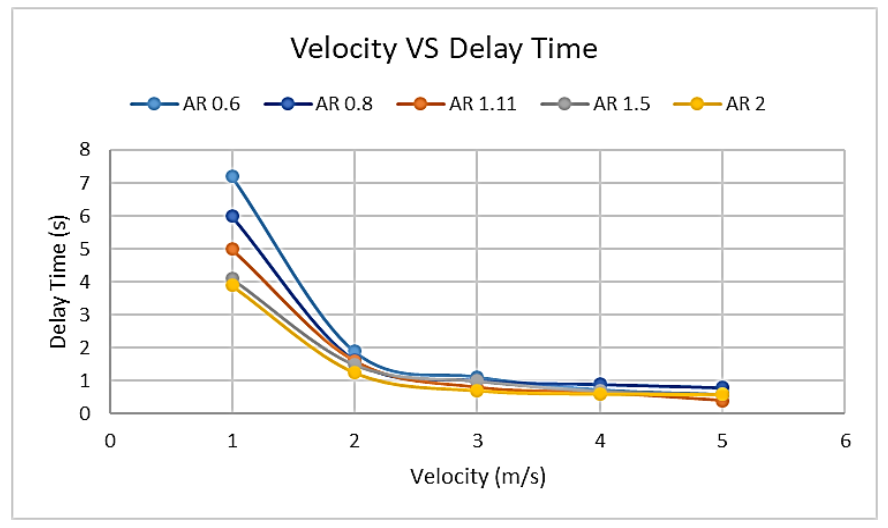

(b)

Fig. 5 Plots of (a) Velocity vs CL (b) Velocity vs Delay Time

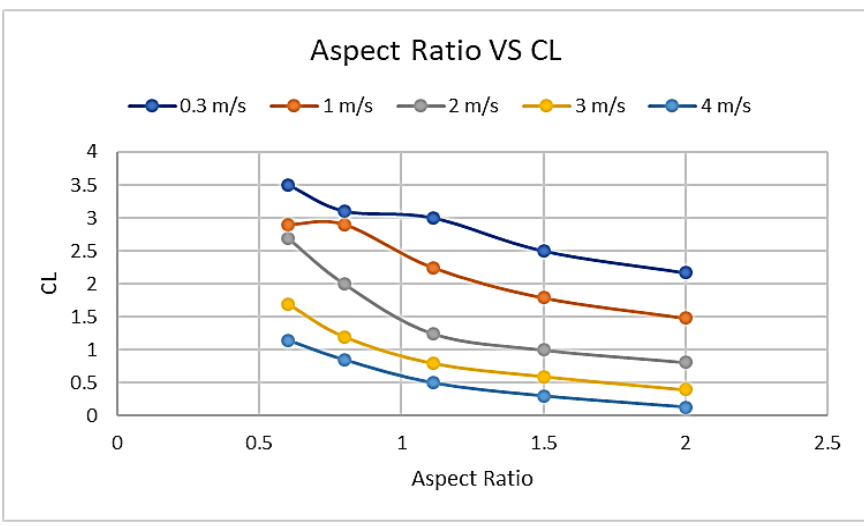

(a)

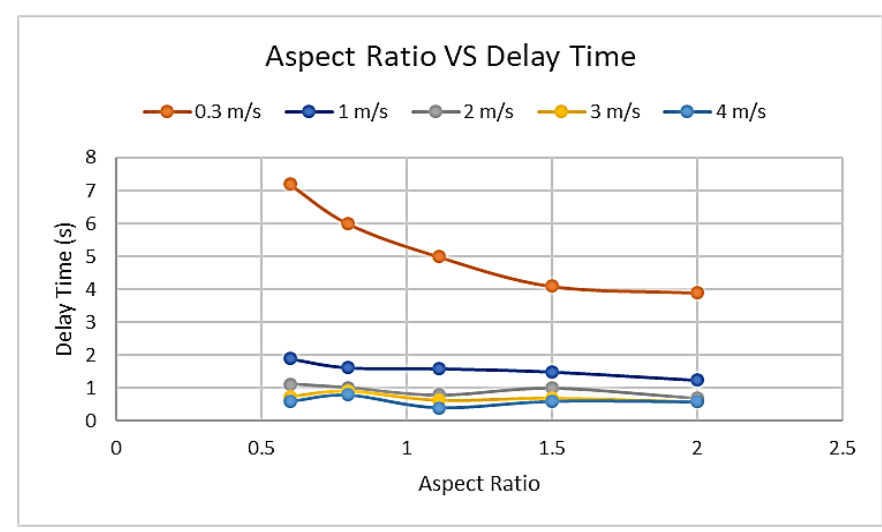

(b)

Fig. 6 Plots of (a) AR vs CL (b) AR vs Delay Time

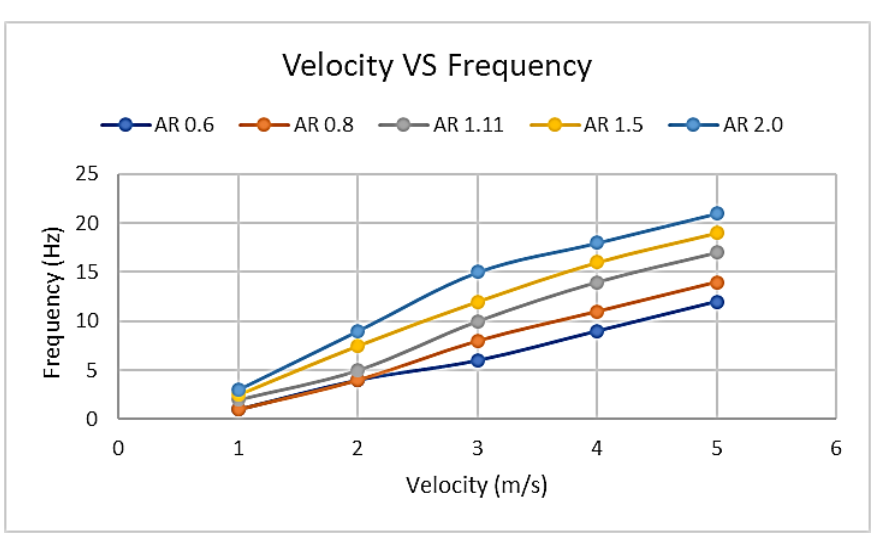

(a)

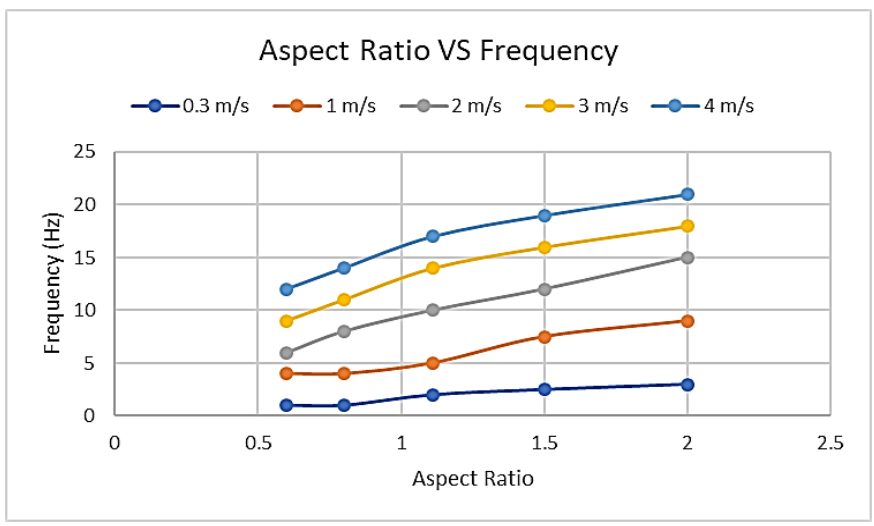

(b)

Fig. 7 Plots of (a) Velocity vs Frequency (b) AR vs Frequency

From Table 1 six different graphs can be obtained in Fig. 5 showing the relations among aspect ratio, lift force, frequency, velocity, and lock-in delay.

From Fig. 5 (a) and (b), it is seen that for a definite aspect ratio, lift force and delay time both decrease with the increase of velocity. Fig. 5 (b) also indicates that delay time is almost constant above $2 \mathrm{~m} / \mathrm{s}$.

From Fig. 6 (a) and (b), it is found that $C_{L}$ and Delay time both decreases with the increasing aspect ratios. There is a drastic reduction in delay time as the velocity increases from $0.3 \mathrm{~m} / \mathrm{s}$ to $1 \mathrm{~m} / \mathrm{s}$.

Again, it is visible from Fig. 7 (a) and (b) that, frequency of vibration most linearly increases with both aspect ratio and velocity. The higher aspect ratio may give higher frequency but it will result in less amplitude of vibration i.e. low power output.

\section{Conclusion}

The selection of the core method of power generation (electromagnetic induction) in the experimental setup is due to the fact that any other complex conversion incorporates more losses in the conversion process. The raw energy conversion rate proved that the concept of VIV based vertical oscillating converter has potential and could be studied further for practical large-scale implementation. The simulation result paved the way for understanding the behavioral pattern of the vibrating cylinder. It is observed that higher velocities produce greater lift force but at the same time the conversion rate i.e. CL decreases. As VIV occurs in laminar open-channel flows, this converter can be applied where the flow velocity is comparatively lower. Also, greater CL for lower velocities is observed. Again, in order to get sufficient power, the flow velocity should be in an optimally 
greater range. This study also revealed that larger aspect ratios produce less CL and the delay time is almost independent of aspect ratios above the velocity of $2 \mathrm{~m} / \mathrm{s}$. Hence, in the case of the application of this converter above a velocity of $2 \mathrm{~m} / \mathrm{s}$, there is no need to consider converters with higher aspect ratios to gain effective conversion. Also for velocities above $2 \mathrm{~m} / \mathrm{s}$, the delay time is negligible. Thus, in practical cases of rivers and canals where the flow could be disturbed frequently, this converter could be applied as immediate lock-in would occur after every disturbance and the hamper in power generation would be negligible. As VIV is a natural occurrence in marine life, this will cause almost no harm to the aquatic environment. Energy can be harnessed from the free-stream which is clean, bio-life friendly, and noise-free.

\section{Acknowledgments}

The work presented in this paper is partially funded by the Department of Mechanical Engineering of Chittagong University of Engineering and Technology.

\section{References}

[1] Pritchard, J.L., 1954. Aerodynamics. Selected topics in the light of their historical development. Theodore von Kármán. Cornell University Press, Ithaca, New York. Oxford University Press, Oxford, 1954. 194 pp. illustrated. 38s. The Aeronautical Journal, 58(528), pp.841-842.

[2] Bernitsas, M.M., Raghavan, K., Ben-Simon, Y. and Garcia, E.M.H., 2008. VIVACE (Vortex Induced Vibration Aquatic Clean Energy): A new concept in generation of clean and renewable energy from fluid flow. Journal of offshore mechanics and Arctic engineering, 130(4).
[3] Modi, P.N. and Seth, S.M., 2019. Hydraulics and Fluid Mechanics Including Hydraulics Machines. Rajsons Publications Pvt. Ltd..

[4] Dorman, T.E., Welna, H. and Lindlauf, R.W., 1968. The application of controlled-vortex aerodynamics to advanced axial flow turbines. Journal of Engineering for Gas Turbines and Power, 90(3) pp.245-250.

[5] Edwards, S.S., Edwards Samuel S, 1985. Wind energy converter utilizing vortex augmentation. U.S. Patent 4,516,907.

[6] Patterson Jr, J.C. and Flechner, S.G., 1985. Exploratory wind-tunnel investigation of a wingtip-mounted vortex turbine for vortex energy recovery. NASA Technical Paper 2468.

[7] Patterson Jr, J.C., National Aeronautics and Space Administration (NASA), 1990. Wingtip vortex turbine. U.S. Patent 4,917,332.

[8] Jensen, D.C., Jensen Donald C, 1994. Energy converter using imploding plasma vortex heating. U.S. Patent $5,359,966$.

[9] Carney, M.E., 2008. Energy capture in flowing fluids. U.S. Patent Application 11/509,667.

[10] Cajas, J.C., Houzeauxa, G., Yáñezb, D.J., MierTorrecillaa, M., 2016. SHAPE Project Vortex Bladeless: Parallel multi-code coupling for Fluid-Structure Interaction in Wind Energy Generation. Available online at www.prace-ri.eu.

[11] Bernitsas, M.M. and Raghavan, K., 2004. Converter of current/tide/wave energy. Provisional Patent Application. United States Patent and Trademark Office Serial, (60/628,252).

[12] Govardhan, R.N., 2000. Vortex-induced vibration of two and three-dimensional bodies. Cornell University. 